\section{Puesta al día sobre la prevalencia mundial de la hepatitis $C$}

Desde que informamos en esta revista acerca de la revisión preliminar de la OMS sobre la hepatitis C (Rev Panam Salud Publica/Pan Am J Public Health 1(5)1997:399), ha aumentado a 130 el número de países y territorios que han notificado el número de casos conocidos a la Organización. No obstante, hasta agosto de 1997 se seguía estimando en alrededor de $3 \%$ la población del mundo infectada por el virus de la hepatitis $\mathrm{C}$ (VHC), lo que se traduce a más de 170 millones de portadores crónicos en riesgo de desarrollar cirrosis o cáncer de hígado, o ambas enfermedades. La alta prevalencia de la hepatitis $\mathrm{C}$ y la necesidad de comprender mejor su epidemiología requieren vigilancia mundial a fin de poder determinar las medidas que deben implantarse para su prevención y control.

El descubrimiento relativamente reciente del VHC en 1989 hace que en la comunidad científica reine todavía cierta incertidumbre con respecto a la evolución natural de la hepatitis $C$, sus consecuencias patológicas, la carga socioeconómica que representa y el tratamiento más apropiado de las formas agudas o crónicas. Tampoco se conoce bien su incidencia a escala mundial porque la infección aguda es con gran frecuencia asintomática. Se sabe, sin embargo, que entre las formas de transmisión más importantes figuran las transfusiones de sangre no tamizada, el uso de instrumentos mal esterilizados y el de agujas compartidas por toxicómanos. También se transmite por vía sexual y perinatal $y$, con menos frecuencia, por medio de las prácticas culturales y sociales que involucran procedimientos percutáneos (por ejemplo, agujerear las orejas u otras partes del cuerpo, la circuncisión y los tatuajes).

De los 28 países y territorios de la Región de las Américas que notificaron casos a la OMS, 17 tienen prevalencias menores de $1 \%$; siete, de 1 a $2,4 \%$; dos, de 2,5 a $4,9 \%$; uno, de 5 a $10 \%$, y uno de más de $10 \%$. Puesto que aún no existe una vacuna antiVHC ni un tratamiento efectivo de bajo costo, la prevención es primordial. Deben, por lo menos, observarse las siguientes medidas de precaución:

- Tamizaje de la sangre y sus productos derivados.

- Aplicación efectiva de precauciones universales y métodos de barrera.
- Eliminación de agujas desechables y esterilización apropiada de material reutilizable como las jeringas.

- Promoción de educación pública sobre los riesgos del uso de material no esterilizado.

Esta puesta al día tiene el objeto de estimular la recolección de nuevos datos más precisos en todas partes del mundo para mejorar el conocimiento epidemiológico de la hepatitis C. (World Health Organization. Hepatitis C: global prevalence, update. Wkly Epidemiol Rec 1997;72:341-344.)

\section{Diferencias epidemiológicas de la infección por Helicobacter pylori en países desarrollados $\mathrm{y}$ en desarrollo}

A principios del decenio de los noventa, nuevos conocimientos sobre el papel que desempeña Helicobacter pylori (HP) en el desarrollo de varias enfermedades digestivas llevaron a un cambio radical en el tratamiento. Pronto se comprobó que HP es la causa más frecuente de gastritis crónica y un carcinógeno tipo I. Se ha informado de la regresión del linfoma gástrico MALT como resultado de la erradicación de HP y un comité de expertos de los Institutos Nacionales de Salud (Estados Unidos de América) ha recomendado ese método como tratamiento estándar inicial en todos los pacientes con úlcera gástrica o duodenal. La recomendación se basa por un lado en la intensa asociación entre la presencia de úlcera y la infección por HP y, por otro, en la cicatrización de úlceras al eliminar la bacteria aunque no se modifique la secreción de ácido gástrico. Ante todo, se observa una reducción notable del riesgo de recurrencia de la úlcera después de erradicar HP.

Los estudios que fundamentan esta revolución terapéutica provienen de los países desarrollados. Por eso, en un artículo de revisión chileno se plantea si es válido aceptarla en países en desarrollo, donde es muy diferente la epidemiología de la infección por HP. Tan común como la caries dental, su prevalencia oscila entre 20 y $40 \%$ en el reducido grupo de países desarrollados, pero entre 70 y $90 \%$ en el inmenso grupo de países en desarrollo. En estos, la incidencia de la infección durante la infancia es tan elevada que la mayoría de la población está infectada al llegar a la edad adulta. Por el contrario, en la 
mayor parte de los países desarrollados la infección parece adquirirse gradualmente a lo largo de la vida, con una tasa aproximada de 0,5 a $1 \%$ al año.

Obviamente, no todas las personas infectadas desarrollan úlceras y esta variabilidad individual aún queda por dilucidar. La respuesta inmunitaria que provoca HP en el huésped no logra eliminar la infección, por lo cual se requiere el uso de antimicrobianos que deben vencer obstáculos como la ubicación extracelular de HP en la superficie luminal de la mucosa gástrica, la acidez y el peristalismo del estómago, la baja tasa de multiplicación de la bacteria y su capacidad de adoptar formas cocoídeas sumamente resistentes. La efectividad de antibióticos in vitro no se relaciona en este caso con su uso in vivo. Una erradicación satisfactoria requiere el empleo combinado de tres a cuatro medicamentos, en varias tomas diarias y por tiempo prolongado. Sin embargo la resistencia primaria a antibióticos, al igual que la intensidad de la infección, pueden determinar una respuesta menos efectiva, especialmente cuando se usa metronidazol, al cual se ha observado una resistencia que llega hasta $80 \%$ en cepas de HP de países en desarrollo.

Los esquemas terapéuticos que producen un alto porcentaje de erradicación de la bacteria en países industrializados suelen tener menos éxito en los países en desarrollo. Las razones parecen ser una mayor frecuencia de la resistencia primaria a los nitroimidazoles, una mayor carga bacteriana y una nueva exposición precoz a la bacteria. Se necesitan estudios locales prospectivos con un número significativo de pacientes para aclarar el peso de estas diferencias, pero por ahora los esquemas recomendables en los países en desarrollo deben incluir un agente antisecretorio y dos antibióticos y terapia de un mínimo de 2 semanas. También es necesario estudiar más a fondo la diferencia entre recidiva y reinfección postratamiento en ambos tipos de países. En cuanto a la estimación de costos, la menor efectividad del tratamiento de erradicación con antibióticos y la frecuencia de reinfección en los países en desarrollo aumentan los costos, pero aun así, una erradicación de solo $50 \%$ supera a las demás terapias disponibles. (Rollán RA. Erradicación de Helicobacter pylori en países en desarrollo. Rev Med Chile 1997;125: 939-949.)

\section{Supervivencia y capacidad ambulatoria de personas de edad avanzada después de cirugía por fractura de cadera}

Las fracturas óseas relacionadas con la edad, especialmente las de cadera, suelen considerarse un gran problema de salud pública. En el frecuentemente citado informe de C. W. Miller (J Bone J Surg 1978; 60A:930-934), solo 51\% de los pacientes con fracturas de cadera pudieron volver a caminar como antes de la lesión, 27\% murieron durante el año siguiente y $22 \%$ sobrevivieron sin capacidad ambulatoria. Los estudios epidemiológicos muestran que el riesgo de morir aumenta en los 6 a 12 meses posteriores a una fractura de cadera. En pacientes de edad avanzada, la tasa de mortalidad oscila entre 14 y $36 \%$ un año después de la fractura y se asocia, según diferentes estudios, con enfermedad sistémica no controlada adecuadamente, con la edad y el sexo (las mujeres sobreviven más tiempo), y con la institucionalización.

Un estudio retrospectivo realizado en Argentina muestra mejores resultados e indica que hay varios factores cruciales independientes de la recuperación, fuertemente vinculados con el estado anterior a la fractura. El estudio describe la experiencia de un equipo de cirujanos que atendieron a 154 mujeres y a 46 hombres por fracturas de cadera unilaterales entre 1979 y 1995. En 7, 127 y 64 casos, respectivamente, se practicaron osteosíntesis y reemplazos parciales y totales de la articulación. Dos pacientes con reemplazo total tuvieron que ser operados de nuevo. Ninguno requirió tratamiento antitrombótico postoperatorio. Nueve mujeres y cuatro hombres sufrieron una segunda fractura, tres de ellos entre los 6 y 12 meses después de la primera, y los 10 casos restantes, de 1 a 6 años después.

La evolución de los pacientes se consideró "buena" cuando pudieron recuperar su capacidad ambulatoria anterior a la fractura; "insatisfactoria", cuando pudieron volver a caminar con bastón $u$ otra ayuda; y "pobre", cuando no pudieron volver a caminar. La supervivencia proporcional a la edad se evaluó con el modelo de riesgo de Cox. Se investigaron las covariables de edad, sexo, tipo de fractura, tipo de prótesis y existencia o no de enfermedades de pronóstico grave. Entre estas se encontraron enfermedades graves de corazón y pulmones, diabetes, hipertensión, cáncer y un caso de hemorragia gastrointestinal masiva. En este estudio, la supervivencia fue función de la edad y del sexo. Las enfermedades importantes, el tipo de fractura y el tipo de prótesis no afectaron significativamente la supervivencia. Esta covariable se descartó, ya que la proporción de enfermedades importantes en los que fallecieron equivalió a $50 \%$, o sea a lo que pudiera ocurrir por azar. La media de la edad al sufrir la fractura fue de 79,3 $\pm 9,8$ años en las mujeres y de 78,7 $\pm 8,8$ en los hombres. Después de ajustar las dos poblaciones a la misma edad promedio de 79 años, las medianas de supervivencia fueron significativamente diferentes: 3,9 y 8,4 en hombres y mujeres, respectivamente. No se observó ninguna diferencia significativa de evolución entre los sexos; fue "buena" en 162 casos ( $81 \%)$, "insatisfactoria" en $15(8 \%)$ y "pobre" en 11 (6\%). En cuanto a supervivencia, 14 de las mujeres fallecieron durante el año 
posterior a la cirugía y ocho se perdieron de vista. De los 46 hombres, nueve murieron durante el año posterior a la fractura, y cinco se perdieron de vista. En $35 \%$ de las mujeres y $55 \%$ de los hombres no se registró la causa de defunción ni pudo determinarse interrogando a los familiares. La media de años de supervivencia en mujeres fue de 7,4 $\pm 0,5 \mathrm{y}$ en hombres de 5,8 $\pm 0,8$. Los resultados obtenidos sugieren que los adelantos en la cirugía han mejorado también la evolución de las fracturas de cadera. Hoy día el tratamiento quirúrgico puede ser una inversión en salud más favorable que las medidas que combinan prevención con tratamiento. (Cipitria JA, Sosa MM, Pezzotto SM, Puche RC, Bocanera R. Outcome of hip fractures among elderly subjects. Medicina (Buenos Aires) 1997;57: 530-534.)

\section{Se intensifica la lucha internacional contra la cepa de influenza A(H5N1)}

El virus H5N1, que puede producir mortandad en las aves, se descubrió por primera vez en 1961 en golondrinas de mar de Suráfrica. Hasta mayo de 1997, lo único que se sabía del virus es que infectaba a varias especies de aves, incluidos los pollos y los patos. Para esa época murieron en Hong Kong, Región Administrativa Especial de China, miles de aves domésticas que habían contraído el virus, pero también se enfermaron con el mismo virus varias personas. El primer caso confirmado fue un niño de 3 años que falleció en mayo. Dos personas que estuvieron en contacto con él desarrollaron la infección más tarde. Uno de ellos, un trabajador de salud, no había estado en contacto con aves ni expuesto al virus en el laboratorio. No obstante, no puede afirmarse que la transmisión haya ocurrido de persona a persona. El segundo caso fue otro niño que asistía a la misma guardería que el caso índice y se conjetura que puede haber sido infectado por el primer niño o expuesto igual que él a las mismas aves. Entre los familiares de los casos no se han visto casos de infección, excepto en una ocasión, por lo cual es de creer que la transmisión de persona a persona no es muy probable. Al 8 de enero de 1998 se habían confirmado 16 casos y se estaban investigando tres más que se sospechaba podían ser causados por el virus. Desde el 28 de diciembre no se han notificado casos nuevos, pero de las personas que enfermaron cuatro han muerto y tres se encuentran gravemente enfermas. El resto se ha recuperado satisfactoriamente.

Los virus aislados de los primeros cuatro pacientes tenían todas las características genéticas del virus aviario $\mathrm{H} 5 \mathrm{~N} 1$, pero solo en dos de ellos se verificó que podían haberse originado en aves. Otros casos parecen haber sido expuestos al virus en el laboratorio. Todos los contactos de casos con- firmados se han recuperado de dolencias similares a la gripe y han tenido resultados de laboratorio negativos a H5N1. Si bien no se ha podido establecer claramente la forma de transmisión de esta enfermedad, los pocos casos encontrados a pesar de la intensa vigilancia sostenida y la ausencia de diseminación en las familias de los casos indican que el virus no se transmite fácilmente. No obstante, los virus A de influenza son notorios por la facilidad con que entran en mutación. Es posible que una mutación produzca un virus $\mathrm{A}(\mathrm{H} 5 \mathrm{~N} 1)$ muy transmisible. Los casos de infección humana comprenden dos tipos levemente diferentes del virus, pero los investigadores no cuentan con pruebas para poder afirmar que ha habido mutación genética. El departamento de salud de Hong Kong mandó sacrificar 1,4 millones de pollos y otras aves y está llevando a cabo estudios epidemiológicos para obtener más información sobre el microorganismo. También se ha prohibido la importación de pollos vivos de China, principal abastecedora de aves. $\mathrm{Al}$ mismo tiempo, las organizaciones internacionales de salud pública están haciendo un gran esfuerzo conjunto para prevenir la dispersión en humanos de esa cepa de influenza. Los centros colaboradores en influenza de la OMS están actualmente trabajando con varias cepas $\mathrm{H} 5$ para preparar virus semilla en caso de que se necesite una vacuna. La preparación de una cepa vacunal puede ocupar varios meses pero, como no se ha comprobado ninguna transmisión de persona a persona, la OMS todavía no ha recomendado la elaboración de una vacuna. Por otra parte, se ha aumentado la vigilancia de la influenza en todos los hospitales y 63 clínicas públicas de salud en Hong Kong. Un equipo de cinco epidemiólogos del Centro Colaborador de la OMS de Referencia e Investigación sobre la Influenza en los Centros para la Prevención y el Control de Enfermedades (CDC) se encuentra investigando sobre el terreno y la OMS también ha destacado allí dos miembros de la División de Vigilancia y Control de Enfermedades Emergentes y otras Enfermedades Transmisibles, de la Región del Pacífico Occidental. Se siguen estudiando las muestras de sangre de los contactos de cuatro personas con infección comprobada y la vigilancia se ha extendido tanto a las aves domésticas como a las silvestres. El Centro Colaborador también ha preparado un juego de reactivos que se enviará dentro de poco tiempo a 82 países para diagnosticar la cepa H5N1. Por el momento, no se justifica imponer restricciones de viaje o cuarentenas. (Organización Mundial de la Salud. International effort to combat new influenza strain stepped up. Comunicado de prensa WHO/92, 15 de diciembre de 1997; Influenza $\mathrm{A}(\mathrm{H} 5 \mathrm{~N} 1)$ in Hong Kong: two new suspect cases. Comunicado de prensa $\mathrm{WHO} / 93,17$ de diciembre de 1997; y Centros para el Control y la 
Prevención de Enfermedades, EUA. Human spread of Hong Kong 'bird flu' unlikely. CNN Interactive, 8 de enero de 1998. URL: http://cnn.com/ HEALTH/9801/08/health.flu.reut/index.html)

\section{El consumo de pescado puede reducir sustancialmente el riesgo de muerte súbita de origen cardíaco}

Según un estudio de cohorte de 11 años llevado a cabo por Albert et al., comer pescado graso por lo menos una vez a la semana puede reducir a la mitad en los hombres el riesgo de muerte súbita de origen cardíaco, es decir, la muerte que sobreviene durante la hora siguiente al comienzo de los síntomas. Esta investigación se realizó como parte del US Physicians' Health Study [Estudio de la salud de los médicos de los Estados Unidos] en 20551 médicos varones de 40 a 84 años de edad que al inicio del estudio estaban exentos de infarto de miocardio, enfermedad cerebrovascular y cáncer. Los sujetos completaron cuestionarios sobre su salud, factores de riesgo de enfermedad cardiovascular, uso de alcohol y vitaminas, consumo de ciertos alimentos y ejercicio. Todos se asignaron aleatoriamente a recibir aspirina o betacaroteno, ambas sustancias o placebo. Durante el seguimiento, la información sobre sucesos cardiovasculares se actualizó cada 6 meses durante el primer año y una vez al año de allí en adelante. A los 12 y 18 meses se les administraron cuestionarios sobre la ingestión de mariscos y pescados y, a los 5 años, un cuestionario sobre el uso actual de suplementos de aceite de pescado. La incidencia de muerte súbita se verificó por medio de registros hospitalarios e informes de los familiares.

Durante el estudio se excluyó a los médicos que fallecieron o no volvieron para completar el cuestionario de los 12 meses, a otros que no incluyeron toda la información pedida y a los que declararon que usaban suplementos de aceite de pescado. Durante todo el estudio sufrieron muerte súbita 133 sujetos. Después de ajustar por edad, tratamiento aleatorio con aspirina y betacaroteno, y factores de riesgo coronario, el consumo de pescado se asoció con una reducción del riesgo de muerte súbita. El límite mínimo perceptible correspondió a una vez por semana, que dio un riesgo relativo multifactorial de 0,48 (IC95\%, 0,24 a 0,96; $P=0,4$ ) en relación con el de los sujetos que consumían pescado menos de una vez al mes. La ingestión estimada de ácidos grasos de mariscos también se asoció con un riesgo reducido de muerte súbita pero sin una tendencia significativa en todas las categorías de consumo aumentado. No hubo ninguna asociación entre el consumo de pescado o la ingestión de ácidos grasos n-3 y la reducción del riesgo total de infarto del miocardio, de la muerte de origen cardíaco no súbita, o de la mortalidad cardiovascular en general. No obstante, el consumo de pescado tuvo una asociación significativa con un riesgo reducido de mortalidad en general.

Los experimentos en perros y primates sugieren que los ácidos grasos n-3 de pescados tienen propiedades que combaten la arritmia. En un estudio retrospectivo de casos y controles, el consumo de pescado graso solo una vez a la semana se asoció con una reducción de $50 \%$ del riesgo de paro cardíaco primario, lo que sugiere efectos antiarrítmicos aun con la ingestión mínima que se vincula con una reducción de la mortalidad por cardiopatía coronaria. No hubo, sin embargo, una clara relación dosisrespuesta y es posible que haya otros nutrientes involucrados en el efecto protector del pescado. $\mathrm{Si}$ ese efecto se debe a los ácidos n-3, la relación ha quedado reducida y oscurecida por un error, ya que se subestimó la ingestión de n-3 debido a falta de información sobre ácidos relacionados en el aceite de soja, aceite de canola y algunas nueces.

La relación inversa entre el consumo de pescado graso y la mortalidad total sin que hubiera una relación significativa con mortalidad cardiovascular indica que puede haber alguna asociación entre ese consumo y otras causas de muerte no cardíacas. Los ácidos n-3 son componentes importantes de todas las membranas celulares, se sabe que tienen efectos antiinflamatorios y pueden ser beneficiosos en casos de colitis ulcerosa, artritis reumatoide y asma. Este es un aspecto del presente estudio que merece investigación ulterior.

En los Estados Unidos todos los años fallecen por muerte súbita de origen cardíaco aproximadamente 250000 personas, de las cuales 55\% no tienen antecedentes de cardiopatía. La mayoría muere antes de llegar al hospital y de las que sí llegan con paro cardíaco, solo 30\% sobreviven. De manera que cualquier reducción sustancial de la arritmia y de la muerte súbita requiere los esfuerzos de la población general y no solo los de individuos que tienen antecedentes de cardiopatías. Si la asociación observada en este estudio es causal, el impacto en la salud pública de comer pescado graso bien valdría la pena. (Albert CM, Hennekens CH, O'Donnell CJ, Ajani UA, Carey VJ, Willett WC, et al. Fish consumption and risk of sudden cardiac death. JAMA [en línea] 1998;279:223-228. URL: http://www.ama-assn.org/ sci-pubs/journals/most/recent/issues/jama/ joc71267.htm) 